\title{
Narrating Transgender Identities: A Linguistic Perspective
}

\author{
ANGELA ZOTTOLA \\ angela.zottola@unina.it \\ University of Naples Federico II
}

\begin{abstract}
This article aims at discussing the relevance of linguistic research with regards to transgender identities representation and self-narration. In fact, this issue of puntOorg International Journal (PIJ) tackles three different perspectives - economic, psychological and linguistic from which the representation and self-narration of transgender and gender non-conforming people working in organizations and business can be analyzed. From the linguistic perspective, interest towards the topic of transgender and gender non-conforming identities has been drawn only recently, despite the relevance language use has on the general understanding of these identity expressions. The discussion will include a qualitative Critical Discourse Analysis of a collection of eight narratives and testimonies of transgender individuals from Italy in relation to their workplace experience and their coming out stories.
\end{abstract}

\section{Introduction}

A first state-of-the-art exploration of the various academic studies related to language and transgender people's identity was conducted about twenty years ago by Don Kulick (1999). In this work, Kulick (1999) outlined the embryonic status in which linguistic studies on transgender identities laid in by the end of the nineteenth century. Moreover, he also stresses on the variety of linguistics approaches that can be applied to transgender identities studies, from phonological/phonetic issues to questions of terminology, classification and identity labels. Nowadays, studies on the (self-)representation of transgender identities have expanded to recognize also the socio-political entailment of the use of language. The analysis of this last aspect has become crucial in our society where gender identity is increasingly becoming concerned with politics and ideologies rather than one's own feelings and self-expression. This behavior reflects, for example, on the growing discrimination, verbal and psychological violence endured by transgender individuals in the workplace. In fact, organization and business environments are being defined as unsympathetic and non-welcoming by transgender individuals (Davies, 2009). This article addresses two main points. On the one hand, it discusses the importance of linguistics research in relation to transgender identities and the way in which they are self-represented within the broader transgender community and also represented by cisgender people. On the other hand, it focuses on the way in which language choices adopted by transgender individuals to narrate their experience in the workplace carry specific underlying ideologies and are sometimes bearers of unintentional stereotyped representations.

In this work, the use of the plural noun identities in relation to the adjective transgender was embraced. This choice mirrors the preference to employ the term transgender in its 
umbrella/inclusive sense, comprehensive of identities labels such as transsexual, trans, $\mathrm{MtF}$, FtM, and more generally speaking all those people, regardless of the label they choose to identify with, whose gender identity or expression do not conform with the gender assigned at birth.

The following sections will address the main points discussed in this article, starting from the context and background related to this investigation, the analysis of a corpus of texts of selfnarrations offered by a group of eight transgender individuals, concluding with suggested further steps in the analysis of transgender identities from a linguistics perspective and the discussion of the findings highlighted in the analysis.

\section{Background and context}

Gender and sexual identities are "constructed, performed, represented and indexed" (Sunderland, 2004: 22) through a process of semiotization, that is to say, that a number of linguistic cues (visual, textual or oral) are involved in the expression of such aspects of identity. Meanwhile, identity is evolving into "an altogether more complex phenomenon as a result of the mobility and diversity in the social worlds" (Preece, 2016: 3); and while its complexity increments so does anything associated with it, like the concept of gender. Identities, therefore gender identities, are embodied within language, primarily because categorization can be done solely through language, the "labels that people attach to themselves and others to signal their belonging" (Joseph, 2016: 19) are actualized through language; secondly because words are the vehicle to express "the indexed ways of speaking and behaving through which [people] perform"(Joseph, 2016: 19) their affiliation; and lastly because other people interpret this performance by understanding that language (Joseph, 2016: 19). These very labels created to fit gender into recognized categories are, and have been for a while now, at a crossroad, as the definition of what gender is keeps changing, adjusting and constantly evolving as years go by, remarkably as society has become more and more aware of the relation between gender and sexuality. Against this backdrop, the study of language in relation to transgender identities whether it is the way transgender people use language, or the way language is used to represent transgender people - becomes fundamental, particularly if we define gender identities as performances (Butler, 2004), and language as one of the major means through which these performances are enacted.

The study of language in reference to gender identities can be traced back to the beginning of the twentieth century. At that time, research in this area consisted mainly of looking at the differences between the way men and women spoke and behaved when communicating. Nowadays, research has moved from thinking about gender with a binary perspective (male vs. female). This scenario was the most popular up until the early ‘90s.

In 1993, William Leap launched the first Lavender Linguistics conference in Washington DC, which signaled the beginning of the study in what is known as Lavender Linguistics (Baker, 2008: 68). It was during one of these conferences, in 1998 that Kulick first presented his research on transgender identity and language.

This can be considered as the beginning of the era in which analysis of language in reference to gender started to give more importance to the way in which, in Milani's words, "individuals do gender in different ways by creatively deploying linguistic means which will allow them to 
orient themselves to available images or models of masculinity and femininity in a specific socio-cultural context" (Milani, 2010: 119).

Like an ever-growing wave, following the development of Lavender Linguistics, these decades see the rise of a new current in the linguistic field: Queer Linguistics. One of the notions, which played a pivotal role in the development of Queer Linguistics, is poststructuralism. Identity, from a post-structuralist point of view, is defined according to its opposite: one thing is something that it is not. Queer Linguistics has the primary aim, in order to make sense of society, of deconstructing those categories, dismantling the binary structure in which identity is put into and understanding the way language is used to construct diverse identities. Queer Theory is based on the fact that identities are fluid and multiple (Baker, 2008: 192) and does not focus on the study of what mainstream society considers as queer but on any identity that distances themselves from mainstream categories. The practice of not considering labels and categories makes identities ideological constructs created through discourse (Barrett, 2002:28). One of the advantages that Queer Linguistics has added to the study of language, gender and sexuality is that it shifted the research from gay and lesbian identity to all those identities which in a way or another are considered to be outside the boundaries of the heteronormative, mainstream and binary categories in which society is enclosed, rejecting the idea of normalization and binary categorizations (Milani, 2017).

The International Journal of Transgenderism, a medical journal launched by Routledge in 1998 and edited by Walter Bockting, was until 1998 the only academic journal focusing specifically on this topic and mainly discussed issues related to gender dysphoria, gender reassignment and the psychological effects of such medical processes on patients. Apart from this medical journal, the list of other works from a medical and psychological perspective is long (see, for example, Delemarre-van de Waal and Cohen-Kettenis, 2006). The same can be said for the field of Cultural Studies, History, Gender and Queer studies, with the work of scholars such as Jack Halberstam (2001, 2003, 2005), Vivienne Namaste (2000), Sandy Stone (1991), Susan Stryker (1994, 2008); similarly, in the field of law with scholars such as Stephen Whittle (1996, 1998a, 1998b, 2016; Witten and Whittle, 2004). In the past decade, we saw the rising of studies that tried to bring all these topics together, like The Transgender Studies Reader, of which Stryker and Whittle published the first volume in 2008. A second volume (Stryker and Aizura, 2013) was published later with the aim of complementing the first one and expanding the horizon to more recent works and emerging trends. Both volumes do not tackle linguistic issues. More recently, in 2014, Duke University press launched the Transgender Reader Quartely, another non-medical scientific journal on issues related to transgender people, edited by Susan Stryker and Paisley Currah, which is at present at its fourth volume.

A distinction on the studies on transgender identities must be acknowledged. In fact, some of the studies focus on the way language is used by transgender people to represent themselves while others aim at investigating the way in which others represent transgender identities. Among the former category, the first linguistic studies on the use of language in relation to transgender identities can be traced back to Kira Hall (1997, 2002, 2013; Hall and O'Donovan, 1996) and to Don Kulick (1998). Hall investigated the way Indian hijras make use of the grammatical gender to perform identity, affect and also hierarchy, while Kulick focused his work on language and identity representation of travesti in Brazil. Later Niko Besnier (2003) investigated the linguistic construction of transgender identities in Tonga. Besnier analyzes the way the English language influenced the Tongan society, which still remains essentially 
monolingual. He concludes that among the minorities using English in that society a big part is constituted by transgender individuals who find in this form of code-switching an escape from marginality and oppression (Besnier, 2003: 296).

More recently, Burnes and Chen (2012) try to shed light on transgender identities by looking at the various definitions and self-representations. Through the use of a mixed methodology, they position transgender identity among multiple identities, proving hypotheses for new approaches to the understanding of these identities.

Zimman (2009, 2013, 2014) makes a rather important contribution to the field, by investigating the language used by transgender men. Zimman discusses transgender people coming out narratives', "on the power of language to redefine the body in the face of compulsory gender and sexual normativity" (Zimman, 2014: 14), on sociophonetics and how the pitch of the voice changed in FtM transgender individuals after the use of testosterone and lastly on the linguistic representation of the gendered body on behalf of transgender men in online communities.

The media have become a crucial source for the analysis of the use of language by transgender people. In particular, the Internet has given researchers a lot of material to discuss. Lexi Webster (2016, Forthcoming) analyzed self-identification of transgender people in the social media platform Twitter and the identity performance by transgender people on webbased fora, demonstrating the non-homogeneity of transgender identities. Laura Horak (2014) looked at the consumption of vlogs created by transgender individuals on YouTube, and how these productions at the same time serve to their creators as forms of acceptance and acknowledgment of their own identities. Lucy Jones (Forthcoming) investigates the identity construction by two transgender vloggers, concluding that they actively use normative discourses to perform their identities.

With regards to the use of language in the representation of transgender identities, the second pattern highlighted previously, the press served as an interesting ground for the exploration of language in relation to transgender identities. An influential work in this area is the study by Paul Baker published in 2014. Here Baker collected a corpus of newspaper articles from the year 2012 and through the use of Corpus Linguistics tools he analyzed the way the British press depicted transgender people in that year. Baker (2014: 233) highlighted that trans people are regularly represented in the press as receiving special treatment, as victims or villains, as involved in relationships or sex scandals, as objects of jokes; he also adds that some positive representations were retrieved but less frequently. Zottola (2018a, 2018b, Forthcoming a), expanding on Baker's (2014) work, focuses her analysis, among other aspects, on the semantic prosody carried by the linguistic choices adopted by the newspapers to represent transgender identities and the way trans people are portrayed as social actors in the British press. Gupta (2018) analyzes misgendering through pronoun use in news reports on Lucy Meadows. More on the press, and its lexical choices when it comes to the representation of transgender people, has been written by Ferraresi (2018), who focuses on citizen journalism and investigates the extent to which those negative stereotypes about transgender people are reversed in citizen journalism.

The November volume of TSQ in 2016 dedicated the whole issues to the ways in which transgender identities are translated. Transgender people are becoming more and more popular on the big and small screen, in fact, cinema and television have a predominant role in the popularization of issues related to transgender identities. Hartner (2015) affirms that 
representation of transgender characters in films tends to realign transgender identity with heteronormative identities, drawing on the notion of love and family. In line with this, Capuzza and Spencer (2016) take into consideration nine scripted US TV series which feature transgender character and conclude that the way transgender people have been represented in the years has evolved from a "wrong body" (Capuzza and Spencer, 2016: 3) narrative to a more diverse and inclusive representation of different transgender identities and subjectivities. Hess (2017) analyzes how aging of transgender people and, more generally, queer people is represented in Transparent (2014). Zottola (Forthcoming b) looks at the linguistic representation of the character of Sophia Burset in Orange is the New Black. She addresses the way the character uses language to talk about herself and the way other cisgender characters use language to talk about Sophia, addressing a comparison between the source language (English) and its translation into Italian. One of the findings of this study highlights how the Italian translation of the scripts tends to tame down some more offensive expressions or parts of dialogues used in the original version. These four examples bring forward the diversity in the representation of transgender identity in television and the cinema. The character of Sophia Burset, and the actress who played this role, Laverne Cox, attracted the attention of quite a few scholars. Finally, Di Martino (2017), for example, analyzes the representation of transgender identity given by the actress and how it influences the way masculinity and femininity are perceived. From the press to social media, from written to (audio)visual, the presence of transgender identities is now substantially part of everyday communication. The analysis of the means through which this presence is linguistically and discursively constructed is seminal for the understanding of these identities, to fight the growing trend of negative stereotypes and to work towards the construction of an inclusive, non-discriminating and non-heteronormative use of language.

\section{Self-narratives in the workplace: an analysis from Italian}

Within the field of self-narration and self-representation of transgender identities, this section describes the linguistics patterns emerged from the analysis of a small corpus of texts offered by transgender people who narrate their experience in the workplace. The corpus includes eight narratives in Italian. Six of the anecdotes are from FtM transgender individuals, one is from an MtF transgender person while in one of the texts it is not possible to identify the gender identity of the speaker. Out of respect for the people who generously offered their contribution to the research presented in this special issue the contributors will remain anonymous.

The texts will be analyzed in the framework of Critical Discourse Analysis (Baker, 2006, 2008; Baker et al., 2013; Fairclough, 1995, 2011; Fairclough and Wodak, 1997), defined as (Fairclough, Mulderrig and Wodak, 2011: 357):

[...] a problem-oriented interdisciplinary research movement, subsuming a variety of approaches, each with different theoretical models, research methods and agenda. What unites them is a shared interest in the semiotic dimensions of power, injustice, abuse, and political-economic or cultural change in society. 
Critical Discourse Analysis (CDA) can be seen as "a dispassionate and objective social science [...] a form of intervention in social practice and social relationships" (Fairclough and Wodak, 1997: 258), which seeks to highlight those hidden and, at times, unintentional ideologies carried by language used in a specific context and a specific pattern.

Without compromising its social scientific objectivity and rigor, CDA openly and explicitly positions itself on the side of dominated and oppressed groups and against dominating groups. (Fairclough, Mulderrig and Wodak, 2011: 358). CDA mainly focuses on textual evidence - from news texts to advertisements, interviews to speeches - and considers the linguistic strategies used in the text. Scholars of CDA start from the assumption that although some of the textual cues may appear normal or neutral on the surface, they are still implicitly ideologically invested. In fact, the peculiarity of CDA in comparison with traditional discourse analysis lies in the aspect of criticality; "[t]he 'critical' principally means unravelling or 'denaturalising' ideologies expressed in discourse and revealing how power structures are constructed in and through discourse" (Machin and Mayr, 2012).

The narratives collected for this analysis are strongly diverse, some of these present a highly poetic narrative, resembling a stream of consciousness but contemporarily elegiac and solemn. Other narratives simply describe the experience, in a nearly aseptic format. Some of the protagonists of the texts wrote a lengthier anecdote, while others were brief in their narratives. The age span of the narrators is also extremely varied from an early adulthood experience to people in their late fifties. Despite the varied background of the writers and their approach to the storytelling of their experience, the eight narratives seem to present a number of common patterns.

The most robust semantic component that emerges from the close reading of the texts is the use of references to the medical field, to the process of transition through hormone therapy, psychological therapy, and gender reassignment surgery. It was common to find terms such as disforia ('dysphoria'), diagnosi ('diagnosis'), cambio di sesso ('sex change'), terapia ('therapy'), condizione ('condition') in contexts such as the following one:

(1) Tentarono anche di imputarmi la separazione per colpa ipotizzando che la mia condizione di transgender fosse geneticamente trasmissibile.

(Trans.: 'They tried to impute on me separation for fault after hypothesizing that my condition as a transgender person could be genetically transmissible'). ${ }^{1}$

The reliance on a medicalized narrative in the narration of their experience arouses one of the major issues that transgender people are forced to deal with in Italy. The lack of terminology, inclusive language, and vocabulary apt to the meaning needed to be conveyed forces transgender people to commit to the use of narratives which continue to associate transgender identities to outdated discourses and understandings of the topic. These linguistics choices are understood by people who are not part of the in-group community as the only way possible to interpret transgender identities and mislead the frivolous reader to the association of transgender identity to a condition, something related to health even a disease.

\footnotetext{
${ }^{1}$ All translations of data are done by the author of the article.
} 
This excerpt also exemplifies another pattern that emerges from the narrative examined here, the feeling of sufferance that accompanies these individuals.

(2) [...] emerge una sofferenza lacerante di dover essere sempre qualcosa che non sei e che non sarei mai stato $[\ldots]$.

(Trans.: 'An excruciating sufferance of always needing to be something that you are not and will never be emerges').

This pattern is often associated to the sadness of having to fake an identity that does not represent them, but also to the fear of not being accepted not only by society more generally speaking but by those who affirm to love you.

Another issue mainly related to Italian is the use of gendered terms. The Italian language requires most nouns and verbs to have a final suffix which signals the gender inflection. The narratives, in all cases except the one with no gender inflections and for which it is not possible to identify the identity of the writer, the presence of both feminine and masculine suffixes and pronouns are found. The use of the two inflections generally follows the history of the transition. In fact, in the light of this, the structure of the narration seems to follow a pattern. There is an opening statement that introduces the narrator and their gender identity and then a recount of their history. The gender inflection and pronouns use generally follow the narration: when the person is describing the period before transition, they use pronouns and gender inflection referred to the sex assigned at birth; when describing moments of their lives after transition, they use pronouns and gender inflections referred to the chosen gender.

In most cases, these narratives tackled the issue of giving up. Giving up happiness, love, family, and work. "Avrei dovuto rinunciare a tutto" (Trans.: 'I would have had to give up everything) says one of the interviewed'); "Sapevo a cosa sarei andato incontro e conoscevo bene il dolore e le sofferenze. [...] ferrite profonde [...] ormai so come farle guarire [...] sono diventato il dottore di me stesso' (Trans.: 'I knew what I was going to face and I knew the pain and sufferance very well. [...] deep wounds [...] by now I know how to fix them [...] I've become my own doctor'). All the narratives conclude with a message of hope, with a positive ending and the realization of their true self, as expressed in example (3) below.

(3) Io penso che bisogna rimanere sempre a testa alta perché non c'è niente di male ad essere finalmente se stessi.

(Trans.: 'I think that we should always keep our head up because there is nothing wrong with finally being the person you feel you are').

The eight narrators manage in the end to find a job, to be accepted in their workplace or to find a way to cope with a partial acceptance of their persona. Unfortunately, I believe that the main reason we are able to analyze these experiences is precisely because, in a way or another, the eight protagonists were able to deal with their context and their experience and emerge in a positive light, an ending that is still nowadays not as popular. 


\section{Conclusion}

Language is a mighty instrument. Not only it conveys meaning, but it shapes our understanding of concepts, modulates the expression of one's ideologies, enables - through specific linguistic choices - to take a stance. On the grounds of the context presented in the second section, it is possible to say that the linguistic interest in the use of language to (self)represent transgender identity is increasingly rising, drawing on different means and manners to use language, which rely not only on the speaker or writer but also on the context in which the language is produced. Despite this acknowledgment, this is still not enough. The narratives analyzed in this work point to the fact that freedom of speech and expression has not been reached yet, especially in a context such as Italy. Mainstream ideologies and the understanding of gender identities in the Italian society still force transgender people to experience painful coming out and difficulties in having a job. Feeling welcomed in the workplace and being accepted as a human being and not a gendered body is still not a common practice.

Kulick (1999) concludes his analysis with an invitation for all linguists to invest more in collecting data about the way transgender people talk or are talked about. Social media, the press, advertisement, television and the cinema permeate our everyday lives and profoundly influence our understanding of society. Therefore, language use needs to be addressed, not only to define the way in which transgender identities are discursively constructed or to identify the linguistic strategies enacted by transgender people to perform their identities, but more importantly to uncover stereotyped, homophobic and non-inclusive usage of language; to investigate the use of terminology related to transgender identities and put an efforts towards the creation and popularization of an inclusive and non-discriminatory use language.

With regards to the way in which transgender identities should be further investigated multimodal practices that mainstream media associate to transgender identities that carry a specific ideology and stance have not been extensively considered yet, as much as other issues related to the structure of language such as the use of gender-neutral pronouns and titles. This work comes as a novelty in terms of the geographical area of inquiry, in fact, so far the focus of studies on transgender identities remains on English language and English-speaking countries. Regardless of the fact that these countries, such as the USA or the UK, and this language (i.e. English) have become a standard and an example to replicate across the world, investigating new geographical areas and other languages might be the key to finding new methods of interpretations and new answers to old questions which still remain unsolved.

\section{Keywords}

Language use; linguistic perspectives; organizations; self-narration; transgender identities.

\section{Reference list}

Baker, P. (2006) Using Corpora in Discourse Analysis, London/New York: Continuum.

Baker, P. (2008) Sexed Texts: Language, Gender and Sexuality, London/Oakville: Equinox Publishing. 
Baker, P. (2014) "Bad Wigs and Screaming Mimis: Using Corpus-Assisted Techniques to Carry out Critical Discourse Analysis of the Representation of Trans People in the British Press", In Contemporary Critical Discourse Studies, C. Hart and C. Piotr (eds), pp. 211-235, London: Bloomsbury.

Baker, P., Gabrielatos, C., McEnery, T. (2013) Discourse Analysis and Media Attitudes: The Representation of Islam in the British Press, New York, NY: Cambridge University Press.

Barrett, R. (2002) “Is Queer Theory Important for Sociolinguistic Theory?", In Language and Sexuality: Contesting Meaning in Theory and Practice, K. Campbell-Kibler, R.J. Podesva, S.J. Roberts and A. Wong (eds), pp. 25-43, Stanford: CSLI Press.

Besnier, N. (2003) "Crossing Genders, Mixing Languages: The Linguistic Construction of Transgenderism in Tonga", In The Handbook of Language and Gender, J. Holmes and M. Meyerhoff, pp. 279-301, Meiden/Oxford/Victoria/Berlin: Blackwell Publishing.

Burnes, T.R., Chen, M.M. (2012) “The Multiple Identities of Transgender Individuals: Incorporating a Framework of Intersectionality to Gender Crossing", In Navigating Multiple Identities: Race, Gender, Culture, Nationality, and Roles, R. Josselson and M. Haraway, pp. 113-128, Oxford: Oxford University Press.

Butler, J. (2004) Undoing Gender, New York, NY: Routledge.

Capuzza, J., Spencer, L. (2016) “Regressing, Progressing, or Transgressing on the Small Screen? Transgender Characters on U.S. Scripted Television Series", Communication Quarterly, 65 (2): 214-230.

Davies, D. (2009) “Transgender Issues in the Workplace: HRD's Newest Challenge/Opportunity", Advances in Developing Human Resources, 11 (1): 109-120.

Delemarre-van de Waal, H., Cohen-Kettenis, P. (2006) “Clinical Management of Gender Identity Disorder in Adolescents: A Protocol on Psychological and Paediatric Endocrinology Aspects", European Journal of Endocrinology, 155: S131-S137.

Di Martino, E. (2017) “Painting Social Change on a Body Canvas: Trans Bodies and their Social Impact", In Queering Masculinities in Language and Culture, P. Baker and G. Balirano (eds), pp. 149-174, London: Palgrave.

Fairclough, N. (1995) Media Discourse, London: Hodder.

Fairclough, N. (2011) “Discursive Hybridity and Social Change in Critical Discourse Analysis", In Genre(s) on the Move: Hybridization and Discourse Change in Specialized Communication, S. Sarangi, V. Polese and G. Caliendo (eds), pp. 11-26, Napoli: Edizioni Scientifiche Italiane.

Fairclough, N. and Wodak, R. (1997) Discourse as Social Interaction, London/New York: SAGE Publications.

Fairclough, N., Mulderrig, J., Wodak, R. (2011) Discourse Studies: A Multidisciplinary, London/New York: SAGE Publications.

Ferraresi, A. (2018) “Who Writes the Story Matters: Transgender Identity through the Lens of Citizen Journalism", In Miss Man? The Adventures of Gender, G. Balirano and O. Palusci (eds), pp. 190-214, Newcastle upon Tyne: Cambridge Scholars Publishing. 
Gupta, K. (2018) "Response and Responsibility: Mainstream Media and Lucy Meadows in a Post-Leveson Context", Sexualities, 1-17. DOI:10.1177/1363460717740259.

Halberstam, J. (2001) “Telling Tales: Brandon Teena, Billy Tipton, and Transgender Biography", In Passing: Identity and Interpretation in Sexuality, Race and Religion, M.C. Sanchez and L. Schlossberg (eds), pp. 13-27, New York, NY: New York University Press.

Halberstam, J. (2003) "The Transgender Look", In The Bent Lens: A World Guide to Gay and Lesbian Film, L. Daniel and C. Jackson (eds), pp. 18-21, Los Angeles, CA: Alyson Books.

Halberstam, J. (2005) In a Queer Time and Place: Transgender Bodies, Subcultural Lives, New York, NY: New York University Press.

Hall, K. (1997) “'Go Suck your Husband's Sugarcane!': Hijras and the Use of Sexual Insult”, In Queerly Phrased: Language, Gender, and Sexuality, A. Livia and K. Hall, pp. 430-460, Oxford: Oxford University Press.

Hall, K. (2002) “'Unnatural' Gender in Hindi”, In Gender Across Languages: The Linguistic Representation of Women and Men, M. Hellinger and H. Bussman (eds), pp. 133-162, Amsterdam: John Benjamins Publishing Company.

Hall, K. (2013) ““It's a Hijra!": Queer Linguistics Revisited”, Discourse \& Society, 24 (5): 634-642.

Hall, K., O’Donovan V. (1996) “Shifting Gender Positions among Hindi-Speaking Hijras”, In Rethinking Language and Gender Research: Theory and Practice, V. Bergvall, J. Bing and A. Freed, pp. 228-266, London: Longman.

Hartner, M. (2015) "Imagining Transgender: Reinscriptions of Normativity in Duncan Tucker's Transamerica and Jackie Kay's Trumpet", FIAR: Forum for Inter-American Research, 8 (1): 109-122.

Hess, L. M. (2017) “'My Whole Life I've Been Dressing up like a Man’: Negotiations of Queer Aging and Queer Temporality in the TV Series Transparent", European Journal of American Studies, 11 (3): 1-19. DOI:10.4000/ejas.11702.

Horak, L. (2014) "Trans on YouTube: Intimacy, Visibility, Temporality", Transgender Studies Quarterly, 1 (4): 572-585.

Jones, L. (Forthcoming) “Discourses of Transnormativity in Vloggers' Identity Construction”, International Journal of the Sociology of Language.

Joseph, J. (2016) "Historical Perspectives on Language and Identity", In The Routledge Handbook of Language and Identity, S. Preece (ed.), pp. 19-33, Oxon: Routledge.

Kulick, D. (1998) Travesti: Sex, Gender, and Culture among Brazilian Transgendered Prostitutes, Chicago, IL: The University of Chicago Press.

Kulick, D. (1999) “Transgender and Language: A Review of the Literature and Suggestions for the Future", The Journal of Lesbian and Gay Studies, 5 (4): 605-622.

Machin, D., Mayr, A. (2012) How to Do Critical Discourse Analysis: A Multimodal Introduction, London: SAGE.

Milani, T. (2010) “What's in a Name? Language Ideology and Social Differentiation in a Swedish Print-Mediated Debate", Journal of Sociolinguistics, 14 (1): 116-142. 
Milani, T. (ed.) (2017) Queering Language, Gender and Sexuality, London: Equinox.

Namaste, V.K. (2000) Invisible Lives: The Erasure of Transsexual and Transgendered People, Chicago, IL: University of Chicago Press.

Preece, S. (ed.) (2016) The Routledge Handbook of Language and Identity, Oxon: Routledge.

Stryker, S. (1994) "My Words to Victor Frankenstein above the Village of Chamounix: Performing Transgender Rage", GLQ: A Journal of Lesbian and Gay Studies, 1 (3): 227-254.

Stryker, S. (2008) "Transgender History, Homonormativity, and Disciplinarity", Radical History Review, 100: 145-157.

Stryker, S. and Whittle, S. (2006) The Transgender Studies Reader, London/New York: Routledge.

Stryker, S. and Aizura, A. (2013) The Transgender Studies Reader, London/New York: Routledge.

Stone, S. (1991) “The Empire Strikes Back: A Post-Transsexual Manifesto", In Body Guards: The Cultural Politics of Gender Ambiguity, J. Epstein and K. Straub, pp. 280-304, New York, NY: Routledge.

Sunderland, J. (2004) Gendered Discourses, Houndmills/Basingstoke: Palgrave MacMillan.

Webster, L. (2016) ““A New Level”: A Corpus-Based Method for the Critical Discourse Analysis of Transgender Self-Identification via Social Media", paper presented at the International Conference Critical Approaches to Discourse Analysis Across Disciplines (CADAAD 2016), Catania, Sicily, Italy, September 5-7.

Webster, L. (Forthcoming) "“I Am I": Self-Constructed Transgender Identities in InternetMediated Forum Communication", In Transgender and Language, E. Di Martino and L. von Flotow (eds), International Journal of the Sociology of Language.

Whittle, S. (1996) "Review of F. Lewins (ed.), Transsexualism in Society: A Sociology of Male-toFemale Transsexuals", Journal of Gender Studies, 5 (2): 236-237.

Whittle, S. (1998a) "Gender Outlaw: On Men, Women and the Rest of Us", Archives of Sexual Behavior, 27 (5): 526-530.

Whittle, S. (1998b) “The Trans-Cyberian Mail Way", Social \& Legal Studies, 7 (3): 389-408.

Whittle, S. (2016) The Ultimate Practice Guide to Transgender and Transsexual Human Rights and Equality Law in the UK, Press for Change.

Witten, T., Whittle, S. (2004) "Transpanthers: The Greying of Transgender and the Law", Deakin Law Review, 9 (2): 504-504.

Zimman, L. (2009) “'The Other Kind of Coming out': Transgender People and the Coming out Narrative Genre", Gender E Language, 3 (1): 53-80.

Zimman, L. (2013) "Hegemonic Masculinity and the Variability of Gay-Sounding Speech: The Perceived Sexuality of Transgender Men", Journal of Language \& Sexuality, 2 (1): 5-43.

Zimman, L. (2014) "The Discursive Construction of Sex: Remaking and Reclaiming the Gendered Body in Talk about Genitals among Trans Men", In Queer Excursions: Retheorizing Binaries in Language, Gender, and Sexuality, L. Zimman, J. Davis and J. Raclaw (eds), pp. 13-34, Oxford: Oxford University Press. 
Zottola, A. (2018a) "Transgender identity labels in the British press (2013-2015). A corpusbased discourse analysis", The Journal of Language and Sexuality, 7(2): 237-262.

Zottola, A. (2018b) “Living as a Woman: The British Press on Trans Identities”, In Miss Man? The Adventures of Gender, G. Balirano and O. Palusci (eds), pp. 168-189, Newcastle upon Tyne: Cambridge Scholars Publishing.

Zottola, A. (Forthcoming a) Transgender Identities in the Press. A corpus-based discourse analysis, London: Bloomsbury.

Zottola, A. (Forthcoming b) "Being Sophia Burset: Translating Transgender Identity on the Tv Series Orange is the New Black", Cultus, Special Issue edited by S. Zanotti and I. Ranzato. 